THE POLITICAL ECONOMY OF THE SPECIAL RELATIONSHIP 



\section{The Political Economy of the Special Relationship}

A NGLO-A MERICAN DEVELOPMENT

FROM THE GOLD STANDARD

TO THE FINANCIAL CRISIS

JEREMY GREEN

PRINCETON UNIVERSITY PRESS

PRINCETON \& OXFORD 
Copyright (C) 2020 by Princeton University Press

Requests for permission to reproduce material from this work should be sent to permissions@press.princeton.edu

Published by Princeton University Press

41 William Street, Princeton, New Jersey o8540

6 Oxford Street, Woodstock, Oxfordshire OX20 1TR

press.princeton.edu

All Rights Reserved

ISBN 978-0-691-19732-6

ISBN (e-book) 978-o-691-20161-o

Library of Congress Control Number 2020936531

British Library Cataloging-in-Publication Data is available

Editorial: Hannah Paul

Production Editorial: Ali Parrington

Jacket/Cover Design: Layla Mac Rory

Production: Erin Suydam

Publicity: Kate Hensley \& Kate Farquhar-Thomson

This book has been composed in Arno

Printed on acid-free paper. $\infty$

Printed in the United States of America

$\begin{array}{llllllllll}10 & 9 & 8 & 7 & 6 & 5 & 4 & 3 & 2 & 1\end{array}$ 